\title{
Study of electrical discharge machining for the parts of nuclear industry usage
}

\author{
Marina A. Volosova, Anna A. Okunkova a, Dmitry E. Povolotskiy \\ AND PAVEL A. PODRABINNIK
}

Moscow State University of Technology "STANKIN", 1 Vadkovsky per., 127994 Moscow GSP-4, Russian Federation

Received 24 September 2015, Accepted 15 October 2015

\begin{abstract}
The research of possibility for production of the thin-wall structure as separator for nuclear needs from electrolytic chrome by electrical discharge machining is shown in this article. The developed technology gives an opportunity to obtain a part with minimal allowance. The machined samples were researched for their defects and their surface depletion.
\end{abstract}

Key words: Electrical discharge machining / technological parameters / SEM / chemical element analyses / chrome

\section{Introduction}

Nowadays there are more and more goals set for mechanical engineering that have to do with getting complex geometric shapes of absolute preciseness out of modern innovative or non-standard materials with minimal losses of material [1]. As an example we may take the task of creating optical or other active elements of the grid-type structure and filling the structure with response elements of the corresponding shape.

These made-to-order details are defined by complex geometric shape; the design technology requires the use of rare and non-standard materials with minimal material losses during the manufacturing process, which eliminates machining. That is why the non-traditional manufacturing methods are often used in production, such as electrophysical and electrochemical machining methods [2].

Today all non-traditional machining methods are performed with the machines equipped with $\mathrm{CNC}$ that controls the movement of the machining tool along its trajectory as well as many process parameters. Every CNC-machine, used for instance for electrical discharge machining, is supplied with database with recommended technological parameters for standard materials. This database is often used by the machine operator during manufacturing preparation process [3]. At the CNC panel the operator selects up-front input values like work material, its height, the number of the EDM electrode passes-through or post-machining required surface criterion along with tool parameters. The CNC system

\footnotetext{
${ }^{a}$ Corresponding author: a.okunkova@stankin.ru
}

automatically assigns the required number of the charged wire passes, process parameters for each of them (around 16 parameters), the discharge manufacturing clearance, automatically updates the trajectory based on the data received etc. The operator is able to correct slightly these parameters during the machining process; however some systems won't allow that.

For non-standard materials such as the new kinds of ceramics, structured with nanoparticles, as well as pure metals, such as $99.99 \%$ electrolytic chrome etc. there is a task of selection of the certain machining modes. The task seems impossible when the goal is to achieve fine finish (up to $R a 0.4$ ) after just one wire pass. Based on this one may conclude that the development of the processing methods of the electrical discharge machining for the parts, made of non-standard and rare materials, is rather urgent.

\section{Task description}

Figure 1 shows the physical form of the separator plate of the device in question, characterized by the complex grid structure and strict requirements for geometrical accuracy that must be made of $99.99 \%$ electrolytic chrome. The dimensions of the product are $\varnothing 92.29 \times 95 \mathrm{~mm}$. The openings in the grid structure are meant for the placement of hexahedral rods $(\varnothing 9.4 \times 93.5 \mathrm{~mm})$. The response elements must be done with geometrical accuracy up to 0.02 in plan view. Roughness must not exceed $R a$ 0.4. Vertical dimensional drift must not exceed \pm 0.1 .

When considering the production options of this type of product, the most reasonable option is the possibility 


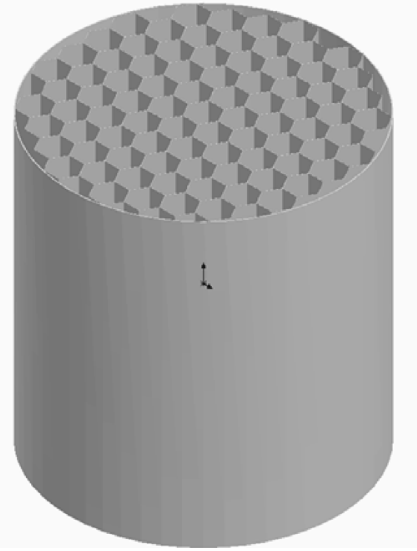

Fig. 1. Model of separator-type object made of $99.99 \%$ electrolytic chrome (85 cells).

of manufacturing the item using two basic methods: selective laser melting of the powder metal and electrical discharge machining.

The first option allows loss of precision in the product's height and the following rework with the tooling method to achieve the required roughness [4], which seems difficult to achieve mechanically under factory conditions, taking into consideration the offered geometry.

The second problem is the powdered chrome material that, according to the grains morphymetry, is the flakeshaped particles. The research shows that the best result of the selective laser melting can be achieved only with the sphere-shaped grains, since only this kind of grain morphymetry provides even absorption of the laser emission by the powder material in the bottom layer, while its flake-shaped structure may reflect the laser beam, bringing the efficiency factor $10-30 \%$ down; it may also create heat overload sites in the machining area, which causes undesirable extra flows of molten metal in the molten pool bath and uneven structures distribution following the cooling-down [5].

When applying electrical discharge machining to the item, one must consider the following tasks: the need to produce the parts in one pass-through of a charged wire; the need to develop a processing method and the size of the discharge gap for the non-standard material [6]; the need to develop special devices and clamping mechanisms for placement and fixation of the work piece on the working table in order to reduce the possible item warp during the machining and other side effects.

For this purpose the possibility of the one passthrough production was researched. It is connected to the fact that similar shape configuration cannot be achieved with the traditional method of the process engineering. There are two options for cutting the hexahedral slots for the shape in question: first question is consecutive cutting out of the entire outline of the slot; second one is cutting the slot out with excess withdrawal.

In the first case the machining of every slot may take up to several days and the entire volume of the slot mate- rial will be transformed into the electrical discharge dust, settling at the bottom of the operating cell. Besides experience has shown that this approach makes difficult to achieve geometric preciseness and low roughness of the incurvation surface of the item [7].

Second option, there is a risk of deformity during the excess withdrawal along the height (when treating the components with the height exceeding $5-7 \varnothing$ of the part). Experience has shown that with multiple passes-through of a charged wire used to achieve the highest quality for the surface, there may be some marks left in the inner cavities due to the tool overcuts or excess chipping (Fig. 2). Also multiple passes-through of a charged wire cause depletion of the surface layer of the part (washing-off the valuable chemical elements), which may affect negatively further exploitation of the part (in compliance to its technological functions) [6].

To reduce the side effects it was necessary to produce cavities with low roughness values in one pass-through. This will help to prevent the overcut of the parts, but will significantly increase the machining time; it requires verification of the machining settings and the size of the discharge gap in accordance with the test data. To fix the excess withdrawal of the cavity specific mounting was used during the machining process that had to be reinstalled along the process at the time of the machining halt, as per the code, and was holding the excess in the cavity.

\section{Equipment}

Electrical discharge machining of the samples for the research purposes was performed with the Seibu M500S equipment (Japan). The basic process parameters are offered in Table 1. Brass wire $\varnothing 0.25 \mathrm{~mm}$ was used as a tool.

Metric studies of the samples were carried out with the non-contact method.

Determining of the roughness parameters, the measures were taken with the profilograph - profilometer Hommel Tester T800 in accordance with the ISO standards. The probe TKU 300/600 was utilized. The length of the sensing lane: $4.8 \mathrm{~mm}$. Measuring range: up to $300 \mu \mathrm{m}$. Gaging error: $\pm 100 \mathrm{~nm}$.

Measurement of geometric parameters. Coordinate inspection machine Werth ScopeCheck 400. Measuring range: $400 \times 200 \times 200$. The lowest presentation value $0.0001 \mathrm{~mm}$. Gaging error: $\pm 3 \mu \mathrm{m}$.

Measurements conditions. All measurements were taken at the constant temperature of $t=23^{\circ}$.

The sub surface research of the samples was performed through the scanning electronic microscope VEGA 3 LMH (Czech Republic) (magnification up to 1,000,000 times) (Table 2).

\section{Results and discussion}

To conduct the research with the work piece made of the electrolytic chrome $20 \mathrm{~mm}$ high, the $10 \times 10 \mathrm{~mm}$ samples (with no allowance for the spark gap) were cut out. 


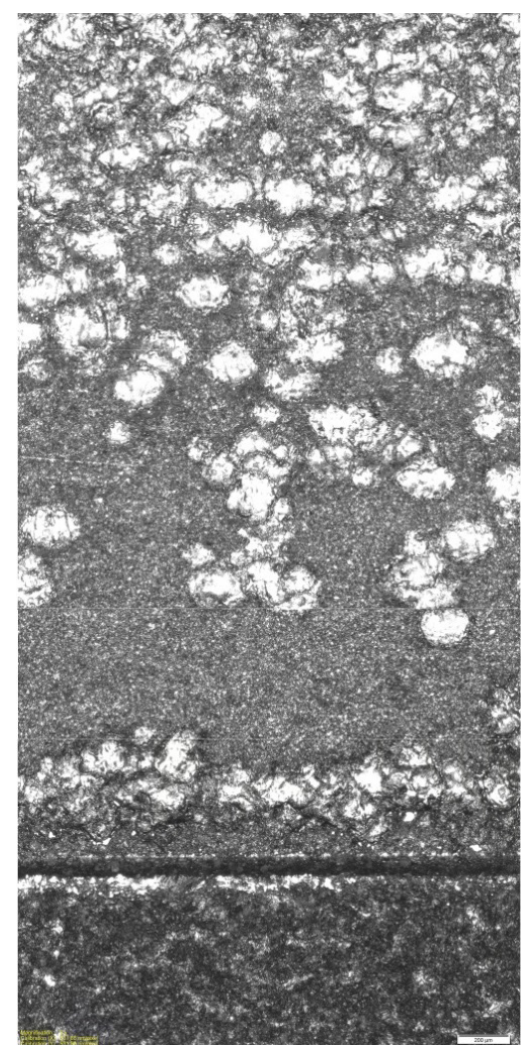

(a)

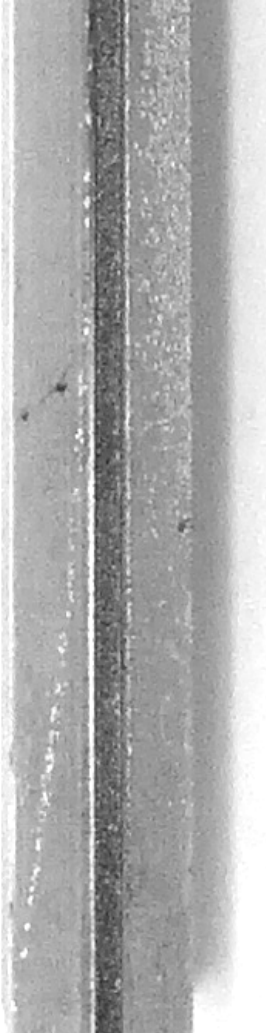

(b)

Fig. 2. Traces of offcut chipping, wire overcutting and burns of work-piece wrapping during D10 $\mathrm{mm} \times 130 \mathrm{~mm}$ stainless steel samples machining: (a) Image received with the optical microscope Olympus BX using $\times 5$ lens; (b) sample appearance.

Table 1. Basic performance specifications of the machine for performing wire spark erosion process.

\begin{tabular}{ccc}
\hline No. & Specs Name & Value \\
\hline 1 & Maximal size of the work piece (length $\times$ width $\times$ height), $\mathrm{mm}$ & $800 \times 650 \times 300$ \\
2 & Maximal weight of the work piece, $\mathrm{kg}$ & 800 \\
3 & Maximal shift along the $X \times Y \times Z$ axes, mm & $500 \times 350 \times 310$ \\
4 & Wire diameter, mm & $0.1 \div 0.3$ \\
5 & Shift along the $U-V$ axes, mm & $\pm 60 \times 60$ \\
6 & Maximal machining angle, degree & \pm 10 \\
7 & Overall machine size, mm & $1810 \times 2245 \times 2070$ \\
8 & Overall weight, $\mathrm{kg}$ & 3500 \\
\hline
\end{tabular}

Process conditions were selected based on the reference information on electrical conductivity for pure metals. Conductivity measures the ability of the substance to conduct electric current. Electrical resistance is a physical quantity that defines the ability of a conductor to resist current flow, and is equal to the ratio of the voltage at the conductor's ends to the intensity of the current, flowing through it. There can be found conductivity and electrical resistance values for some materials in Table 3 [6]. Conductivity values for chrome are to be calculated.

The manufacturers of the electrical discharge equipment offer the preliminary developed process variables for machining the certain materials: copper, aluminum, steel, graphite, tungsten carbide. The authors have chosen the process conditions closest in conductivity for the following materials (the data recorded were for the third pass through): copper, aluminum and steel (as a check sample).

To select process conditions for the chrome work pieces they made 10 specimens for every kind of material. The number of the specimens totaled to 30 pieces. During the machining they could observe frequent rupture of the wire in the process production of the chrome specimen under the conditions designed for copper. 
M.A. Volosova et al.: Mechanics \& Industry 16, 706 (2015)

Table 2. General specification for the SEM VEGA 3 LMH.

\begin{tabular}{cc}
\hline Specs Name & Value \\
\hline Electron-emitting source: & tungsten cathode with thermal emission \\
Resolution (SE): & $3 \mathrm{~nm}$ at $30 \mathrm{~kW} ; 8 \mathrm{~nm}$ at $3 \mathrm{~kW}$ \\
Collision cell exit potential: & from $200 \mathrm{~W}$ up to $30 \mathrm{~kW}^{-1}$ \\
Scanning rate: & from 20 ns up to 10 ms.pixel $^{-1}$ \\
\hline
\end{tabular}

Table 3. Conductivity and electrical resistance for some materials, exposed to electrical discharge machining at the $+20{ }^{\circ} \mathrm{C}$ temperature.

\begin{tabular}{ccc}
\hline Material & Conductivity, $\mathrm{Sm}_{\mathrm{m}} \mathrm{m}^{-1}$ & Electrical Resistance, $\Omega . \mathrm{m}$ \\
\hline Copper & 58100000 & 0.000000018 \\
Chrome & 42000000 & 0.000000027 \\
Aluminum & 37000000 & 0.000000028 \\
Tungsten & 18200000 & 0.000000054 \\
Cast Steel & 7690000 & 0.13 \\
Graphite & 125000 & 0.000013 \\
\hline
\end{tabular}

The specimens' dimensions were measured and their roughness was evaluated (Table 4). Linear dimensions are offered up to three decimal digit, since the manufacturers of the electrical discharge machines usually indicate the value of the discharge gap up to three decimal digit.

The measurements results indicated that the most suitable processing method for the electrical discharge machining of the chrome work pieces is the processing methods developed for copper. In this case the material loss after the one-pass machining will be minimal and the minimal size of the discharge manufacturing clearance $0.262 \mathrm{~mm}$ (not accounting for the electrode wire the size of the discharge gap would be $0.012 \mathrm{~mm}$ ). There are certain limits for the roughness indicators for all three specimens, it is impossible to improve them significantly through any other possible methods and avoid surface depletion. To stabilize the process of the electrical discharge machining of the chrome work pieces under processing parameters developed for copper, some additional experimental works were conducted. During the experimental work two key machining parameters were reduced; those parameters affected the stability of the electroerosion process and the breakage of the tool: the feeding speed of the wire in the working area $S_{\mathrm{G}}$ (within the range of 3 to $20 \mathrm{~mm} \cdot \mathrm{min}^{-1}$ ) and the tension of the charged wire $W_{\mathrm{T}}$ (within the range of 40 to $60 \mathrm{~N} . \mathrm{mm}^{-2}$ ). The best results in terms of the wire breakage along the toolpath were achieved at $S_{\mathrm{G}}=5 \mathrm{~mm} \cdot \mathrm{min}^{-1}$ and $W_{\mathrm{T}}=40 \mathrm{~N} \cdot \mathrm{mm}^{-2}$. Thus the recommended conditions were developed for electrical discharge machining of the $99.99 \%$ electrolytic chrome work pieces up to $20 \mathrm{~mm}$ high; the conditions are displayed in Table 5.

After that sub surface research of the work piece was conducted (Fig. 3). The research indicated that the depletion of the electrolytic chrome could be observed at a distance of $4 \mu \mathrm{m}$ from the work piece surface. The presence of copper and zinc could be explained by the fact that machining electrode was made of brass. The researches constructed graph for other chemical elements, yet their percentage ratio in the cut is so small, that the authors considered them insignificant in terms of the whole picture demonstrating sub surface depletion of the work pieces. Figure 4 shows allocation of the chemical elements in the layer of the work pieces.

Further an enlarged image of the work piece range after the electrical discharge machining of the chrome work pieces under the developed process conditions is received (Fig. 5). The image shows pores, cracks, hardened molten pool drops as a result of discharge channel affect during the machining.

A chemical analysis of an isolated surface region was carried out (Table 6). The presence of a large quantity of oxygen can be explained by the oxidation of the chemical elements in the process of electric erosion chemical reactions over water. The presence of chlorine and potassium can be explained by the chemical composition features of the used dielectric; meanwhile copper and zinc are present because of chemical content of wire-electrode.

\section{Conclusion}

As a result we have received the samples of the chrome work pieces using the method of electrical discharge machining, which allowed us to make a conclusion about the recommended process conditions for machining, including the size of the process discharge gap.

The research for the samples that indicated the depletion of the subsurface layer for the depth of $4 \mu \mathrm{m}$, which was the consequence of the electrical discharge machining physics, were conducted.

Acknowledgements. The work was performed within the framework of the Resolution of the Government of the Russian Federation dated 9 April 2010 No. 220 "On measures taken to attract key scientists to Russian educational institutions of higher professional education and scientific establishments of state academies of science and state research centers of the 
M.A. Volosova et al.: Mechanics \& Industry 16, 706 (2015)

Table 4. Results of the geometric measurements and roughness evaluation for the electrolytic chrome specimens.

\begin{tabular}{ccccc}
\hline $\begin{array}{c}\text { Process } \\
\text { variables for: }\end{array}$ & $\begin{array}{c}\text { Measurement } \\
\text { average, } \mathrm{mm}\end{array}$ & $\begin{array}{c}\text { Roughness parameter } \\
R a, \mathrm{mcm}\end{array}$ & $\begin{array}{c}\text { Roughness parameter } \\
R z, \mathrm{mcm}\end{array}$ & $\begin{array}{c}\text { Roughness parameter } \\
R_{\max }, \mathrm{mcm}\end{array}$ \\
\hline Copper & 9.738 & 1.18 & 8.68 & 10.57 \\
Aluminum & 9.697 & 1.07 & 6.49 & 8.02 \\
Steel & 9.667 & 1.08 & 7.43 & 8.94 \\
\hline
\end{tabular}

Table 5. Recommended process conditions for electrical discharge machining of the chrome work pieces with minimal material loss.

\begin{tabular}{ccccccccccc}
\hline EDM parameters & $V_{0}$ & $V_{\mathrm{G}}$ & $S_{\mathrm{G}}$ & $C_{\mathrm{S}}$ & $\mathrm{I}$ & $T_{\mathrm{OFF}}$ & $H_{\mathrm{S}}$ & $W_{\mathrm{S}}$ & $W_{\mathrm{T}}$ & $\Delta$ \\
\hline Value & 90 & 43 & 5 & 110 & 3 & 8 & 42 & 40 & 40 & 0.262 \\
\hline
\end{tabular}

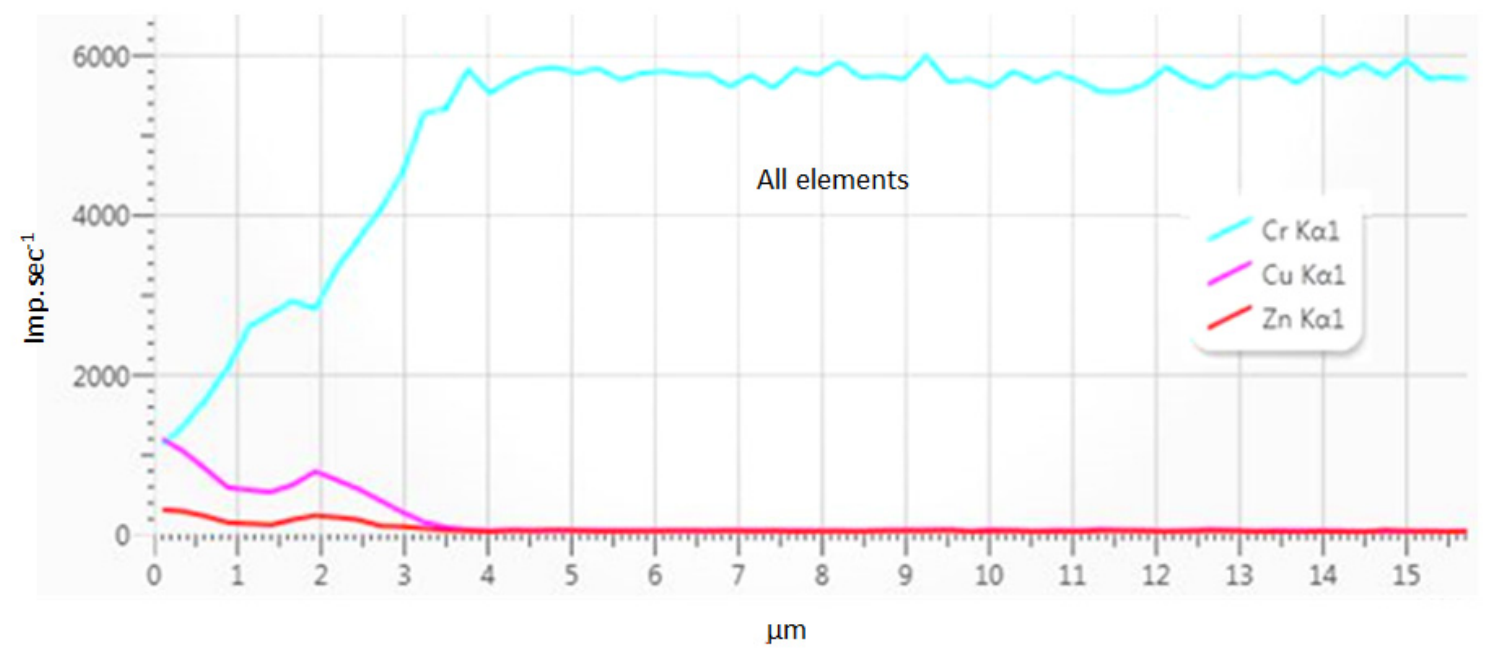

Fig. 3. Allocation of the basic chemical elements in the subsurface of the samples.

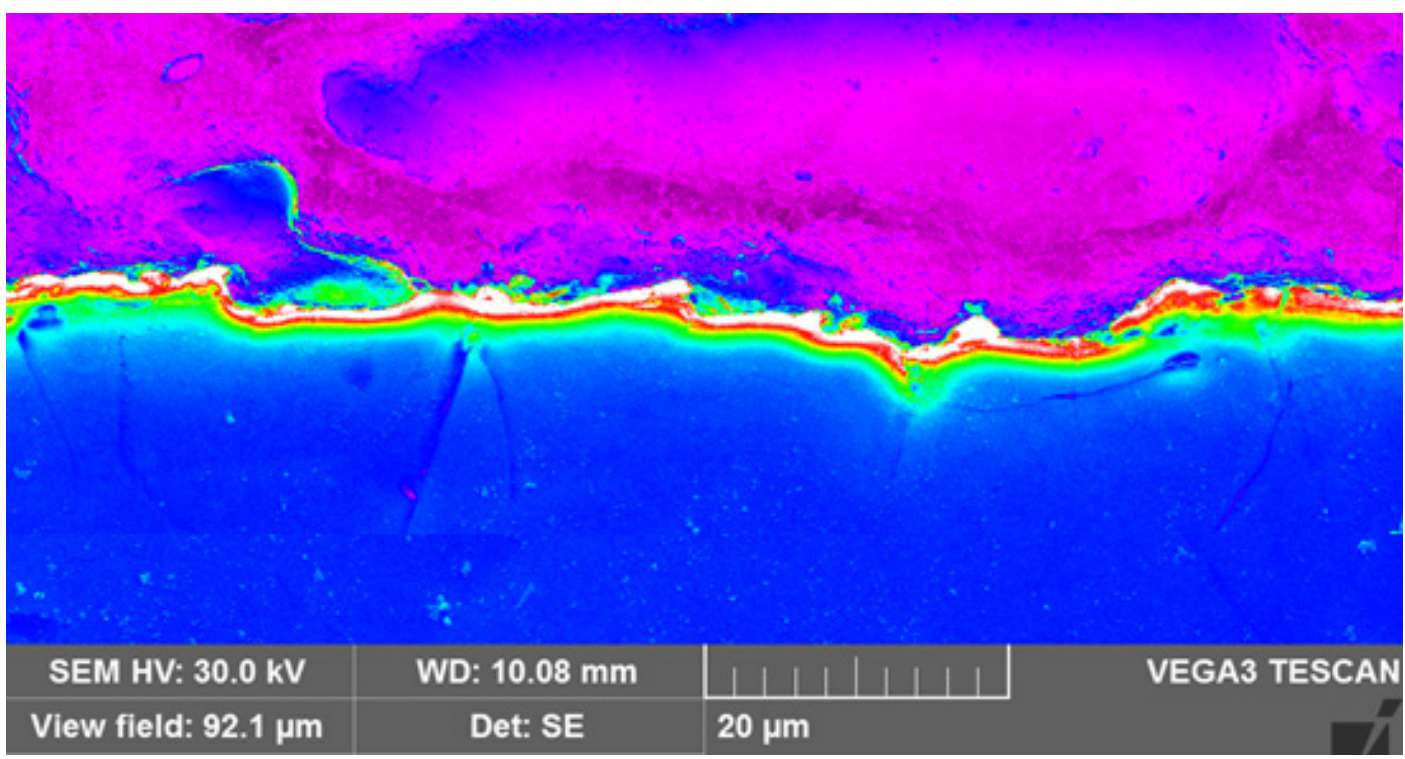

Fig. 4. SEM image showing the allocation of the chemical elements in the sub surface layer of the electrolytic chrome work pieces following the electric discharge machining. 
Table 6. Chemical analysis of the isolated area of the surface layer following the electrical discharge machining.

\begin{tabular}{ccc|ccc}
\hline \multicolumn{3}{c}{ Chemical composition } & \multicolumn{3}{c}{ Standardized chemical composition } \\
\hline Chemical element & Weight \% & Sigma weight \% & Chemical element & Weight \% & Sigma weight \% \\
\hline $\mathrm{Cr}$ & 76.44 & 0.20 & $\mathrm{Cr}$ & 76.64 & 0.18 \\
$\mathrm{Cu}$ & 10.38 & 0.14 & $\mathrm{Cu}$ & 10.40 & 0.13 \\
$\mathrm{Zn}$ & 3.38 & 0.12 & $\mathrm{Zn}$ & 3.39 & 0.12 \\
$\mathrm{O}$ & 9.10 & 0.13 & $\mathrm{O}$ & 9.13 & 0.12 \\
$\mathrm{Cl}$ & 0.28 & 0.03 & $\mathrm{Cl}$ & 028 & 0.03 \\
$\mathrm{~K}$ & 0.16 & 0.03 & $\mathrm{~K}$ & 0.16 & 0.03 \\
Total & 99.74 & - & Total & 100.00 & - \\
\hline
\end{tabular}

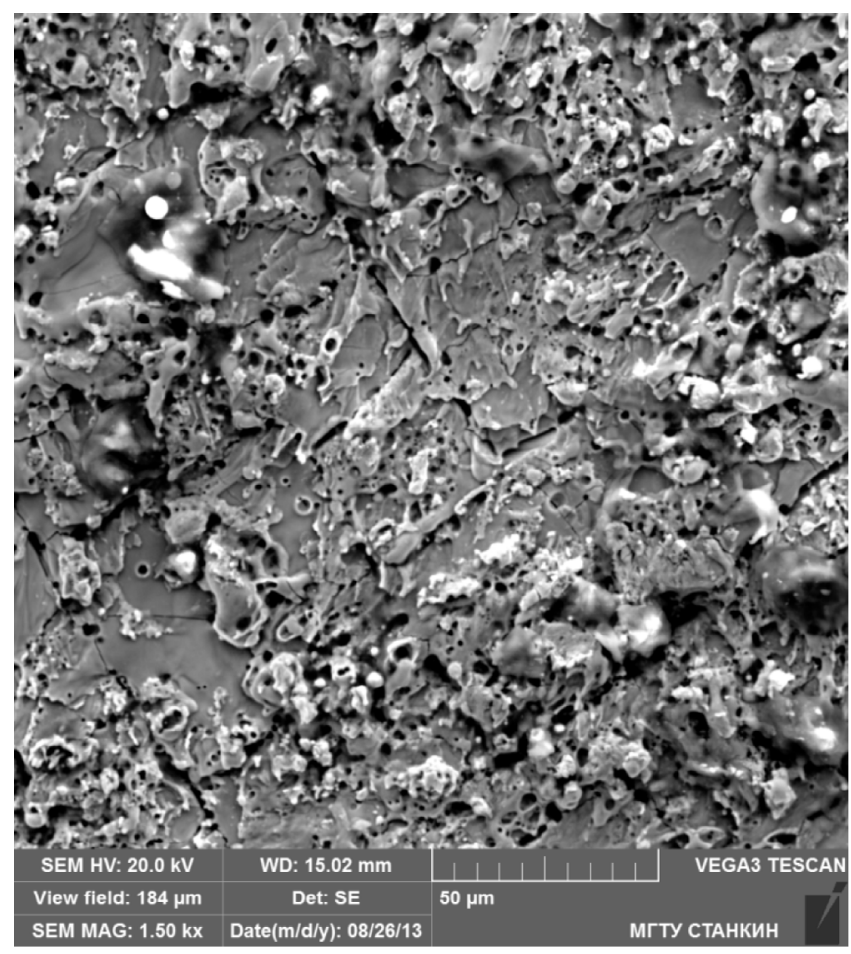

Fig. 5. SEM image, showing the surface condition after the electrical discharge machining of the chrome work pieces.

Russian Federation" (Agreement No. 14.B25.31.0012 dated 26 June 2013). The work is carried out on the equipment of the Center of collective use of MSTU "STANKIN" with financial support of the Ministry of Education and Science of Russian Federation, the Agreement No. 14.593.21.0004 of 04.12.2014, the unique identifier of the project RFMEFI59314X0004.

\section{References}

[1] A. Okunkova, M. Volosova, P. Peretyagin, Y. Vladimirov, I. Zhirnov, A.V. Gusarov, Experimental approbation of selective laser melting of powders by the use of nonGaussian power density distributions, Physics Procedia 56 (2014) 48-57

[2] M.A. Volosova, Influence of vacuum-plasma nitride coatings on contact processes and a mechanism of wear of working surfaces of high-speed steel cutting tool at interrupted cutting, J. Friction Wear 34 (2013) 183-189

[3] L. Esteban-Tejeda, L.A. Díaz, C. Prado, B. Cabal, R. Torrecillas, J.S. Moya, Calcium and Zinc Containing Bactericidal Glass Coatings for Biomedical Metallic Substrates, Int. J. Mol. Sci. 15 (2014) 13030-13044

[4] A. Centeno, V.G. Rocha, B. Alonso, A. Fernández, C.F. Gutierrez-Gonzalez, R. Torrecillas, A. Zurutuza, Graphene for tough and electroconductive alumina ceramics, J. Eur. Ceramic Soc. 33 (2013) 3201-3210

[5] L.A. Díaz, M.A. Montes-Morán, P.Y. Peretyagin, Y.G. Vladimirov, A. Okunkova, J.S. Moya, R. Torrecillas, Zirconia-alumina-nanodiamond composites with gemological properties, J. Nanopart. Res. 16 (2014) 1-9

[6] A.S. Vereschaka, S.N. Grigoriev, E.S. Sotova, A.A. Vereschaka, Improving the Efficiency of the Cutting Tools Made of Mixed Ceramics by Applying Modifying Nanoscale Multilayered Coatings, Adv. Mater. Res. 712 (2013) 391-394

[7] A.A. Vereschaka, S.N. Grigoriev, A.S. Vereschaka, A.Y. Popov, A.D. Batako, Nanoscale multilayered composite coatings for cutting tools operating under heavy cutting conditions, Procedia CIRP 14 (2014) 239-247 